\title{
Biyodizeldeki Suyun Reçine ile Uzaklaştırılması: Adsorpsiyon İzotermi, Kinetiği ve Termodinamik İncelemesi
}

\author{
Zeynep Çelik Okumuş ${ }^{1}$, Tuba Hatice Doğan ${ }^{1 *}$ \\ ${ }^{1}$ Atatürk Üniversitesi, Mühendislik Fakültesi, Kimya Mühendisliği Bölümü, Erzurum, Türkiye (ORCID: 0000-0002-4463-3104) \\ ${ }^{1 *}$ Atatürk Üniversitesi, Mühendislik Fakültesi, Kimya Mühendisliği Bölümü, Erzurum, Türkiye (ORCID: 0000-0001-8369-9416)
}

(İlk Geliş Tarihi 5 Mart 2019 ve Kabul Tarihi 27 Mart 2019)

(DOI: 10.31590/ejosat.535977)

ATIF/REFERENCE: Okumuş, Z. Ç. \& Doğan, T. H. (2019). Biyodizeldeki Suyun Reçine ile Uzaklaştırılması: Adsorpsiyon İzotermi, Kinetiği ve Termodinamik İncelemesi. Avrupa Bilim ve Teknoloji Dergisi, (15), 561-570.

$\ddot{O} \mathbf{z}$

Fosil kökenli yakıtların kullanımına ilişkin ciddi çevresel kaygılar, her geçen gün alternatif temiz yakıtlara olan ilgiyi artırmaktadır. Biyodizel, uygun bir katalizör eşliğinde, bir alkolle trigliseritlerin transesterifikasyonu yoluyla üretilen, temiz, biyolojik olarak bozulabilen, toksik olmayan ve yenilenebilir bir yakıttır. Biyodizel üretimi sırasında, yan ürün olarak oluşan gliserin ayrıldıktan sonra, ham biyodizelin belli uluslararası yakıt standartlarını (EN 14214 ya da ASTM D6751) karşılaması için saflaştırılması gerekir. Biyodizelde safsızlıkların varlığı, sadece motor performansını önemli ölçüde etkilemekle kalmaz, aynı zamanda onun kullanımı ve depolanmasını da zorlaştırır. Bu nedenle ham biyodizelin saflaştırılması bir zorunluluk olarak karşımıza çıkar. Ham biyodizeli saflaştırmak için, hem ıslak hem de kuru yıkama yapılabilmesine rağmen, genellikle kullanılan yöntem sslak yıkama (su ile yıkama) yöntemidir. Ancak bu yöntemde kullanılan suyun, biyodizelden çok iyi uzaklaştırılması gerekir. Biyodizel üretimi için yağların geleneksel transesterifikasyonunda, su her zaman olumsuz etkiler yaratır. Biyodizeldeki suyun varlığı, sabun oluşumuna neden olur, katalizörü tüketir, katalizörün etkinliğini azaltır ve bunların tümü düşük dönüşüme neden olur. Ayrıca üretilen yakıtın kalitesini de olumsuz etkiler.

Bu çalışmada, biyodizeldeki suyun, katyonik Dowex HCR-S iyon değiştirici reçine ile adsorpsiyon mekanizması çalısıllmış ve prosesin adsorpsiyon dengesi, adsorpsiyon kinetiği ve adsorpsiyon termodinamiği incelenmiştir. Bu kapsamda Langmuir, Freundlich, Temkin ve Dubinin-Radushkevich izotermleri denenmiş ve deneysel verilere en uygun izotermin, $\mathrm{R}^{2}$ değeri 0.997 olan Langmuir izotermi olduğu bulunmuştur. Ayrıca, maksimum adsorpsiyon kapasitesi, $53.48 \mathrm{mg} \mathrm{g}^{-1}$ olarak tespit edilmiştir. Kinetik verilerin analizleri, yalancı birinci mertebe ve yalancı ikinci mertebe kinetik modelleri kullanılarak yapılmıştır. Elde edilen sonuçlar, adsorplama prosesinin, yalancı ikinci mertebe kinetik modele en iyi uyduğunu göstermiştir. Çalışmada, ayrıca adsorpsiyon termodinamiği de incelenmiştir. Buna göre, adsorpsiyon prosesinin kendiliğinden gerçekleştiği $\left(\Delta \mathrm{G}^{0}<0\right)$ ve ekzotermik olduğu $\left(\Delta \mathrm{H}^{\circ}<0\right)$ belirlenmiş ve Dowex HCR-S katyonik reçinenin biyodizelden su adsorpsiyonu için, uygun bir adsorbent olduğuna karar verilmiştir.

Anahtar Kelimeler: Biyodizel, Dowex HCR-S reçine, su adsorpsiyonu, izoterm, kinetik, termodinamik.

\section{Removal of Water from Biodiesel with Resin: Isothermal, Kinetic and Thermodynamic Investigation of Adsorption}

\begin{abstract}
The serious environmental concerns about the use of fossil-sourced fuels has increased the interest in alternative clean fuels with each passing day. Biodiesel is a clean, biodegradable, non-toxic and renewable fuel produced by transesterification of triglycerides with an alcohol in the presence of a suitable catalyst. During production of biodiesel, after by-product glycerin is removed, raw biodiesel must
\end{abstract}

\footnotetext{
* Sorumlu Yazar: Atatürk Üniversitesi, Mühendislik Fakültesi, Kimya Mühendisliği Bölümü, Erzurum, Türkiye, ORCID: 0000-0001-8369-9416, hatice@atauni.edu.tr
} 
be purified to reach certain international fuel standards (EN 14214 or ASTM D6751). The presence of impurities in biodiesel does not only significantly affect motor performance, but simultaneously makes use and storage difficult. As a result, purification of raw biodiesel is a necessity. To purify raw biodiesel, in spite of the use of both wet and dry washing, generally the wet washing method (with water) is used. However, the water used in this method must be removed very thoroughly from the biodiesel. Water always causes negative effects on traditional transesterification of oils in production of biodiesel. The presence of water in biodiesel causes the formation of soap, consumes the catalyst, reduces the efficiency of the catalyst and this all leads to low transformation. Additionally, it negatively affects the quality of the fuel.

In this study, the adsorption mechanism of the water in the biodiesel with the cationic Dowex HCR-S ion exchange resin was studied and the adsorption equilibrium, adsorption kinetics and adsorption thermodynamics were investigated for the process. Within this scope, the Langmuir, Freundlich, Temkin and Dubinin-Radushkevich isotherms were used and the most appropriate isotherm for experimental data was found to be the Langmuir isotherm with $\mathrm{R}^{2}$ value 0.997 . Additionally, maximum adsorption capacity was identified as 53.48 $\mathrm{mg} \mathrm{g}^{-1}$. Kinetic data were analyzed using pseudo-first order and pseudo second-order kinetic models. The results obtained show the adsorption process fitted the pseudo-second order kinetic model best. The study also investigated the adsorption thermodynamics. Accordingly, the adsorption process was determined to occur spontaneously $\left(\Delta \mathrm{G}^{\mathrm{o}}<0\right)$ and be exothermal $\left(\Delta \mathrm{H}^{\mathrm{o}}<0\right)$. It was concluded that Dowex HCR-S cationic resin was an appropriate adsorbent for adsorption of water from biodiesel.

Keywords: Biodiesel, Dowex HCR-S resin, water adsorption, isotherm, kinetics, thermodynamics.

\section{Giriş}

Biyodizel, bitkisel ve hayvansal yağlar gibi yenilenebilir yerel kaynaklardan üretilen temiz bir yakıttır. Petrol bazlı dizel yakıta kıyasla, biyolojik olarak bozunabilir olması, toksik olmaması, yüksek alevlenme noktasına sahip olması ve çok daha az $\mathrm{CO}_{\text {ve }} \mathrm{SO}_{2}$ emisyonuna sahip olması gibi avantajları, onun iyi bir alternatif yakıt olmasını sağlar (Kanca and Temur, 2016).

Biyodizel en yaygın olarak transesterifikasyon reaksiyonu ile üretilir. Transesterifikasyonda, bitkisel ya da hayvansal yağ, uygun bir katalizör (genellikle $\mathrm{NaOH}$ ya da $\mathrm{KOH}$ gibi alkali katalizörler) eşliğinde etil/metil alkol ile reaksiyona girer. Reaksiyonun sonunda, biyodizel olarak adlandırılan etil/metil ester fazı ile yan ürün olarak gliserin fazı oluşur. Bu iki faz, ağırlık farkından yararlanarak birbirinden ayrılır (Shadid and Jamal, 2011). Transesterifikasyonla üretilen ham biyodizel, serbest ve toplam gliserin, sabun, metaller, metanol, serbest yağ asitleri, katalizör, su ve gliseritler gibi safsızlıklar içerir. Yüksek seviyedeki safsılıklar motorun ömrünü azaltabilir (Hayyan ve ark, 2010) ve ayrıca, üretilen biyodizelin yakıt olarak kullanılabilmesi için belli uluslararası standartları (EN 14214 ya da ASTM D6751) karşılaması gerekir. Bu nedenle, ham biyodizelin saflaştırılması çok önemlidir.

Ham biyodizeli saflaştırmak için daha geleneksel olarak kullanılan yöntem, su ile yıkamadır. Su, ham biyodizeldeki katalizör atıkları ve sabun oluşumu gibi safsızlıkları uzaklaştırabilir (Atadashi, 2015). Ancak, biyodizelin üretimi ve saflaştırılması sırasında suyun varlığı, biyodizelin depolanması ve dizel motorlarda kullanımı sırasında oldukça önemli problemlere sebep olur. Bu problemler, özellikle alkali katalizörlü transesterifikasyon işlemi sırasında biyodizel üretimindeki zorluklar (sabun oluşumu, katalizörün tüketimi, katalizör etkinliğinde azalma ve bunların sonucu olarak da düşük dönüşüm), biyodizel kalitesindeki bozulma, yanma 1sısında azalma, yakıt sisteminin parçalarında korozyon ve hidroliz reaksiyonunun hızlanması gibi sorunlardır (Atadashi ve ark, 2012; Kusdiana ve Saka, 2004). Bahsedilen pek çok problem göz önüne alındığında, biyodizeldeki suyun uzaklaştırılmasının önemi anlaşılmaktadır.

Geleneksel yöntemle biyodizel saflaştırılırken, gliserinden ayrılan ham biyodizel, üç kez saf su ile yıkanır, her bir yıkamadan sonra 7-8 saat beklenir, ağırlık farkından yararlanarak altta biriken yıkama suları biyodizelden ayrılır. Biyodizelde kalan fazla su, 70-80 ${ }^{\circ} \mathrm{C}^{\prime}$ de, bir döner evaparatörde vakum altında yaklaşık 1 saat kadar tutularak uzaklaştırılır (Ma ve Hanna, 1999; Andrei, 2016). Veya daha az uygulanan yöntemle, biyodizelin uygun bir adsorbent madde yardımıyla önce adsorpsiyonu sağlanır ve daha sonra süzme yoluyla kurutulur (Veljkovic, Bankovic-llic ve Stamenkovic, 2015). Fazla suyun uzaklaştırılması için kullanılan daha geleneksel yöntemin zaman kaybı ve yüksek enerji sarfiyatı gibi dezavantajları bulunmaktadır. Bu nedenle biyodizel saflaştırması için, bazı çalışmalarda uygun adsorbentler ya da iyon değiştirici reçineler kullanılmaktadır. Bu prosesler, filtrasyon, fiziksel adsorpsiyon ya da iyon değişimi mekanizmasına dayanmaktadır (Alves ve ark, 2016; Wall ve ark, 2011).

Literatürde biyodizelden farklı bileşenleri uzaklaştırmak için, araştırmacılar, farklı adsorbentler (Faccini ve ark, 2011; Özgül-Yücel ve Türkay, 2003) ya da iyon değiştirici reçineler (Berrios ve ark, 2011; Shibasaki-Kitakawa ve ark, 2013) kullanmışlar ve bu maddelerin biyodizel saflaştırmasında adsorbent olarak kullanılmasının uygunluğunu araştırmışlardır.

Bu çalışmada ise, Dowex HCR-S katyonik reçine kullanılarak biyodizeldeki suyun adsorpsiyonu incelenmiştir. Bunun için prosesin adsorpsiyon izotermleri, kinetiği ve termodinamiği araştırılmıştır.

\section{Materyal ve Metot}

\subsection{Materyaller}

Biyodizel üretmek için kullanılan ayçiçek yağı, yerel bir marketten satın alınmıştır. Metanol ve KOH katalizörü sırasıyla Merck ve Flake' den temin edilmiştir (İkisi de \%99.9 saflıkta). Adsorbent olarak kullanılan katyonik reçine (Dowex HCR-S), Fluka'dan temin 
edilmiş ve reçinenin bazı özellikleri Tablo 1' de verilmiştir. Ayrıca reçinenin BET (Brunauer, Emmett and Teller) yüzey karakterizasyon analizi de yapılmış ve reçinenin BET yüzey alanı, $4.6594 \mathrm{~m}^{2} / \mathrm{g}$ olarak bulunmuştur.

Tablo 1. Dowex HCR-S reçinenin özellikleri

\begin{tabular}{ll}
\hline Parametreler & Değeri \\
\hline Tipi & Asit katyon \\
Toplam değiştirme kapasitesi, min. & $1.9 \mathrm{eq} / \mathrm{mL}$ \\
Tane boyutu & $300-1200 \mu \mathrm{m}$ \\
pH & $0-14$ \\
Maksimum çalışma sıcaklı̆̆ & $120^{\circ} \mathrm{C}$ \\
Tanecik yoğunluğu & $1.3 \mathrm{~g} / \mathrm{mL}$ \\
Fiziksel formu & Uniform tanecik boyutunda küresel boncuklar \\
\hline
\end{tabular}

\subsection{Ayçiçek Yağından Biyodizel Üretimi}

Mekanik karıştırıcı, geri soğutucu ve sabit sıcaklık su sirkülatörü bağlanmış olan $1000 \mathrm{~mL}$ 'lik ceketli cam bir reaktöre, $700 \mathrm{~mL}$ ayçiçek yağı koyulmuş ve yağ $60{ }^{\circ} \mathrm{C}$ ' ye 1sıtılmıştır. Daha sonra, yağın ağırlıkça \% 0.75 ' i kadar $\mathrm{KOH}$ katalizörü metanolde (Metanol/yağ molar aranı= 5/1) çözülmüş ve 600 rpm'lik karıştırma hızında karışmakta olan reaktöre ilave edilerek reaksiyon başlatılmıştır. 1 saatlik reaksiyon süresinin sonunda, reaktör içeriği bir ayırma hunisine alınmış ve belirli bir süre sonunda altta biriken gliserin fazı, üstte bulunan metil ester fazından (biyodizel) ayrılmıştır. Daha sonra, metil ester fazı üç kez saf su ile yıkanmıştır. Her bir yıkamadan sonra, ayırma hunusinin alt kısmında biriken yıkama suları metil ester fazından ayrılmıştır. Bu işlemden sonra metil ester fazı, içindeki az bir miktar kalan suyu uzaklaştırmak için reçineyle muamele edilmek üzere bekletilmiştir.

\subsection{Reçine ile Biyodizeldeki Suyun Adsorpsiyonu}

Adsorpsiyon deneyleri de biyodizel üretimi için kullanılan deney sisteminde yapılmıştır. Burada, $250 \mathrm{~mL}$ 'lik ceketli cam bir reaktörün içerisine, $100 \mathrm{~mL}$ biyodizel koyulmuştur. Reaktör içeriği istenilen sıcaklığa 1sıtılmıştır. Daha önceden $100^{\circ} \mathrm{C}^{\prime}$ deki bir etüvde belirli bir süre kurutulmuş ve nem kapmaması için desikatörde bekletilmiş olan reçineden belirli bir miktar reaktöre eklenmiş ve karışım, 400 rpm karıştırma hızında, istenilen sürede karıştırılmıştır. Belirlenen sürenin sonunda sistem durdurulmuş ve biyodizelden hızlıca bir mikro enjektör yardımıyla numune alınmıştır. Alınan numunelerdeki su miktarı, bir su tayin cihazı (Karl Fischer coulometrik titratör, GR Scientific Cou-Lo Aquamax KF Moisture Meter) yardımıyla belirlenmiştir. Reçineyle muamele edilmeden önce, ham biyodizel numunelerinin su içerikleri de aynı şekilde tayin edilmiştir. Analizler yapılırken, ham biyodizelin başlangıç konsantrasyonları ve denge konsantrasyonları kaydedilmiştir. Adsorpsiyon izotermleri,1398, 1578, 1649 ve 2553 mg/L'lik farklı su konsantrasyonlarına sahip biyodizele ağırlıça \%6 reçine ilave edilerek belirlenmiştir.

\section{Araştırma Sonuçları ve Tartışma}

\subsection{Farklı Parametrelerin Etkileri}

Reçine yardımıyla biyodizelden suyun uzaklaştırılması için; reçinenin ön kurutma süresi $(0,1,2,3,4$ ve 5 saat için), reçinenin temas süresi $\left(10,20,30,40,50\right.$ ve 60 dakika için), sıcaklık $\left(15,28,40\right.$ ve $50^{\circ} \mathrm{C}$ için) ve reçine miktarı (ağırlıça \%0.5, \%1, \%2, \%5, $\% 6, \% 7$ ve \%8 için) olmak üzere dört parametre belirlenmiş ve bu parametrelerin etkileri başka bir makalemizde (Çelik-Okumuş, Doğan ve Temur, 2019) ayrıntılı bir şekilde tartışılmıştır. Çalışmanın sonuçları göstermiştir ki; biyodizelden en fazla su, $15^{\circ} \mathrm{C}$ sıcaklık, 4 saat reçinenin ön kurutulma süresi, ağırlıç̧a \%6 reçine miktarı ve 50 dakika temas süresi şartlarında adsorplanmıştır ve bu parametre değerlerinde biyodizeldeki suyun \%92.78' i uzaklaştırılmıştır.

\subsection{Adsorpsiyon İzotermleri}

Adsorpsiyon izotermi, sabit sicaklık ve ph’ da, adsorbent üzerine adsorplanan madde miktarı ( $\mathrm{q}_{\mathrm{e}}$, mg $\left.\mathrm{g}^{-1}\right)$ ile çözeltide adsorplanmadan kalan madde konsantrasyonu ( $\mathrm{Ce}, \mathrm{mg} \mathrm{L}^{-1}$ ) arasındaki denge durumunu ifade eden grafiklerdir. Bu izotermler, bilinen bir miktardaki adsorplayıcı ile farklı konsantrasyonlarda hazırlanmış olan çözeltileri dengeye ulaştırarak elde edilebilmektedir. Adsorpsiyon izotermini tanımlamak için yaygın olarak kullanılan eşitlikler, Langmuir, Freundlich, Temkin ve Dubinin-Radushkevich (D-R) eşitlikleridir. Bu eşitlikler yardımıyla, adsorbentin yüzey özellikleri ve adsorplayıcı-adsorplanan arasındaki ilgi tanımlanabilir. Ayrıca, maksimum adsorpsiyon kapasitesi, adsorpsiyon yoğunluğu ve adsorpsiyon 1sısı da belirlenebilir (Elmorsi ve ark, 2014). Bu çalışmada, denge datalarını tanımlamak için yukarıda ifade edilen eşitliklerin lineer formları kullanılmıştır. 


\subsubsection{Langmuir İzotermi}

Langmuir izoterm modeli (Eşitlik 1), adsorpsiyonun homojen bir yüzey üzerinde ve tek tabakalı olarak gerçekleştiğini varsayar. Aynı zamanda Langmuir, bütün aktif noktaların adsorplanacak moleküllere karşı aynı enerji ve eşit ilgiye (afinite) sahip olduklarını da kabul eder (Langmuir, 1918).

$$
\frac{C_{e}}{q_{e}}=\frac{1}{q_{m} K_{L}}+\frac{C_{e}}{q_{m}}
$$

Burada, Ce, biyodizeldeki suyun denge konsantrasyonu $\left(\mathrm{mg} \mathrm{L}^{-1}\right)$, qe, dengedeki adsorpsiyon kapasitesi $\left(\mathrm{mg} \mathrm{g}^{-1}\right), \mathrm{K}_{\mathrm{L}}$, Langmuir sabiti $\left(\mathrm{L} \mathrm{mg}^{-1}\right)$ ve qm, reçinenin maksimum adsorpsiyon kapasitesi ( $\left.\mathrm{mg} \mathrm{g}^{-1}\right)$.

Ayrıca, Langmuir izoterminin önemli özelliklerini tanımlamak için, $R_{L}$ boyutsuz faktörü (Eşitlik 2) kullanılabilir. Eğer, $R_{L}>1$ ise adsorpsiyon uygun değildir, $\mathrm{R}_{\mathrm{L}}=1$ ise doğrusal, $0<\mathrm{R}_{\mathrm{L}}<1$ ise adsorpsiyon uygundur ya da $\mathrm{R}_{\mathrm{L}}=0$ ise proses tersinmezdir.

$$
R_{L}=\frac{1}{1+K_{L} C_{o}}
$$

Burada, $\mathrm{C}_{0}$, ham biyodizeldeki su konsantrasyonu $\left(\mathrm{mg} \mathrm{L}^{-1}\right)$.

Langmuir izoterm incelemesi eşitlik 1 kullanılarak yapılmıştır. Burada, Ce' ye karşı Ce/qe' değerleri doğrusal olarak grafik edilmiş (Şekil 1-a) ve bu grafiğin eğimi ve kaymasından ise qm ve $\mathrm{K}_{\mathrm{L}}$ değerleri hesaplanmıştır. Tablo 2' de verilen $\mathrm{R}_{\mathrm{L}}$ değeri ise Eşitlik 2 kullanılarak hesaplanmıştır.

\subsubsection{Freundlich İzotermi}

Freundlich izoterm modeli (Eşitlik 3), adsorpsiyonun çok tabakalı olduğunu varsayar. Ayrıca, adsorplayıcı yüzeyinin, adsorpsiyon alanları ve enerjisi bakımından heterojen olduğunu kabul eder.

$$
\ln q_{e}=\ln K_{F}+\frac{1}{n} \ln C_{e}
$$

Burada, $\mathrm{K}_{\mathrm{F}}\left(\left(\mathrm{mg} \mathrm{g}^{-1}\right)\left(\mathrm{L} \mathrm{mg}^{-1}\right)^{1 / n}\right)$ ve n, sırasıyla adsorpsiyon kapasitesi ve yoğunlukla ilgili Freundlich eşitlik sabitleridir. Prosesin tipi n parametresi ile belirlenir. $\mathrm{n}=1$ ise, proses doğrusaldır, $\mathrm{n}>1$ olduğunda kimyasal, $\mathrm{n}<1$ olduğunda ise fizikseldir (Gündüz ve Bayrak, 2017).

Freundlich izoterm incelemesi Eşitlik 3 kullanılarak yapılmıştır. Burada, lnCe' ye karşı lnqe doğrusal olarak grafik edilmiş (Şekil 1-b) ve bu grafiğgin eğimi ve kaymasından ise $\mathrm{K}_{\mathrm{F}}$ ve $\mathrm{n}$ değerleri hesaplanmış ve Tablo 2' de verilmiştir.

\subsubsection{Temkin İzotermi}

Temkin izotermine göre, tüm moleküllerin adsorpsiyon ısısındaki azalış, doğrusal bir düzende meydana gelir. Bu da bağlanma enerjisinin homojen olduğunu gösterir (Temkin ve Pyzhev, 1940). Bu izotermi ifade eden eşitlik aşağıda verilir.

$$
\begin{aligned}
& q_{e}=\frac{R T}{b} \ln K_{T} C_{e} \\
& q_{e}=\frac{R T}{b} \ln K_{T}+\frac{R T}{b} \ln C_{e} \\
& q_{e}=B_{T} \ln K_{T}+B_{T} \ln C_{e}
\end{aligned}
$$

Burada, $\mathrm{B}_{\mathrm{T}}=\mathrm{RT} / \mathrm{b}$ ' dir. b, Temkin izoterm sabiti ve $\mathrm{K}_{\mathrm{T}}$, denge bağlanma sabitidir $\left(\mathrm{Lg}^{-1}\right)$.

Temkin izotermi, Eşitlik [4-6] kullanılarak incelenmiştir. Burada, lnCe' ye karşı qe doğrusal olarak grafik edilmiş ve Şekil 1-c' de verilmiştir. $\mathrm{Bu}$ doğrunun eğimi ve kaymasından yararlanarak $\mathrm{B}_{\mathrm{T}}$ ve $\mathrm{K}_{\mathrm{T}}$ sabitleri bulunmuştur (Tablo 2).

\subsubsection{Dubinin- Radushkevich (D-R) izotermi}

Dubinin ve Radushkevich (D-R) izotermi, heterojen bir yüzey üzerindeki potansiyel değişim teorisine dayanır (Dubinin ve Radushkevich, 1947). (D-R) izoterm modeli şu şekilde yazılabilir; 


$$
\begin{aligned}
& q_{e}=q_{m} \exp \left(-K_{D R}\left[R T\left(1+\frac{1}{C_{e}}\right)\right]^{2}\right) \\
& \ln q_{e}=\ln q_{m}-K_{D R} \varepsilon^{2} \\
& \varepsilon=R T \ln \left[1+\frac{1}{C_{e}}\right] \\
& E=\frac{1}{\sqrt{2 K_{D R}}}
\end{aligned}
$$

Burada, R, gaz sabiti (8.314 $\left.\mathrm{J} \mathrm{mol}^{-1} \mathrm{~K}^{-1}\right)$, T, mutlak sicaklık $(\mathrm{K}), \mathrm{K}_{\mathrm{DR}}$, adsorpsiyon enerjisi ile ilgili izoterm sabiti, qm, teorik adsorpsiyon kapasitesi ve $\varepsilon$, Polanyi potansiyelini gösterir. Ortalama adsorpsiyon enerjisi (E), adsorpsiyon mekanizmasını tahmin etmemize yardım eder. Eğer E değeri, 8-16 kjmol-1 ise, adsorpsiyon prosesi iyon değişimi ile karakterize edilir, $\mathrm{E}<8 \mathrm{kjmol}^{-1}$ ise adsorpsiyon fiziksel, $20<\mathrm{E}<40 \mathrm{kjmol}^{-1}$ ise adsorpsiyon kimyasal olarak düşünülebilir (Gündüz ve Bayrak, 2017).

D-R izotermi incelenirken, Eşitlik [7-10] kullanılmıştır. Burada, potansiyel enerjinin karesine $\left(\varepsilon^{2}\right)$ karşı, lnqe doğrusal olarak grafik edilmiş (Şekil 1-d) ve bu doğrunun kayması ve eğiminden qm ve $K_{D R}$ sabitleri bulunmuştur (Tablo 2).

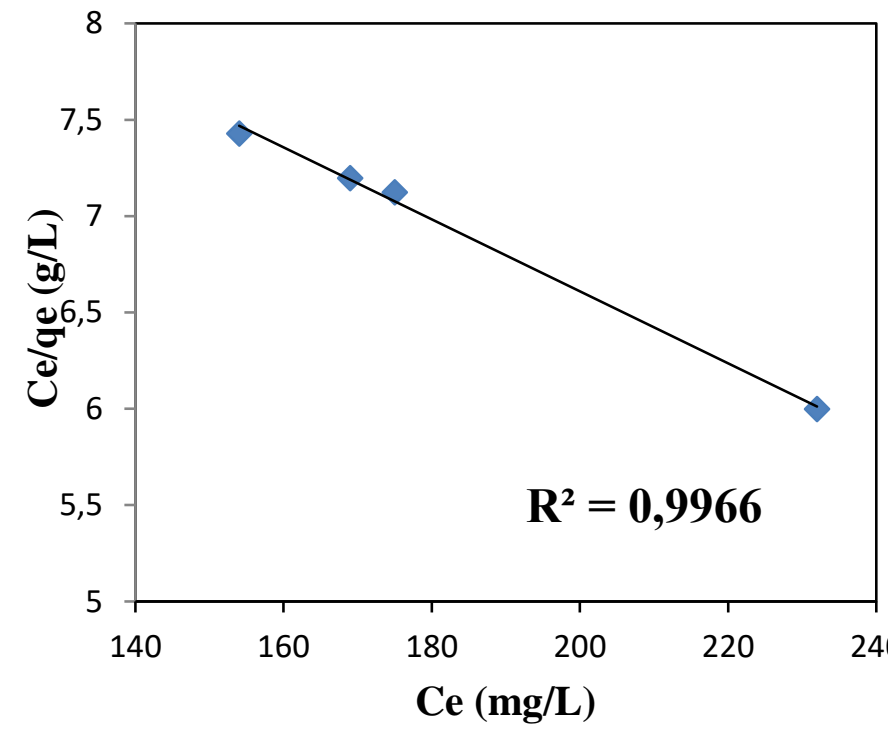

(a) Langmuir

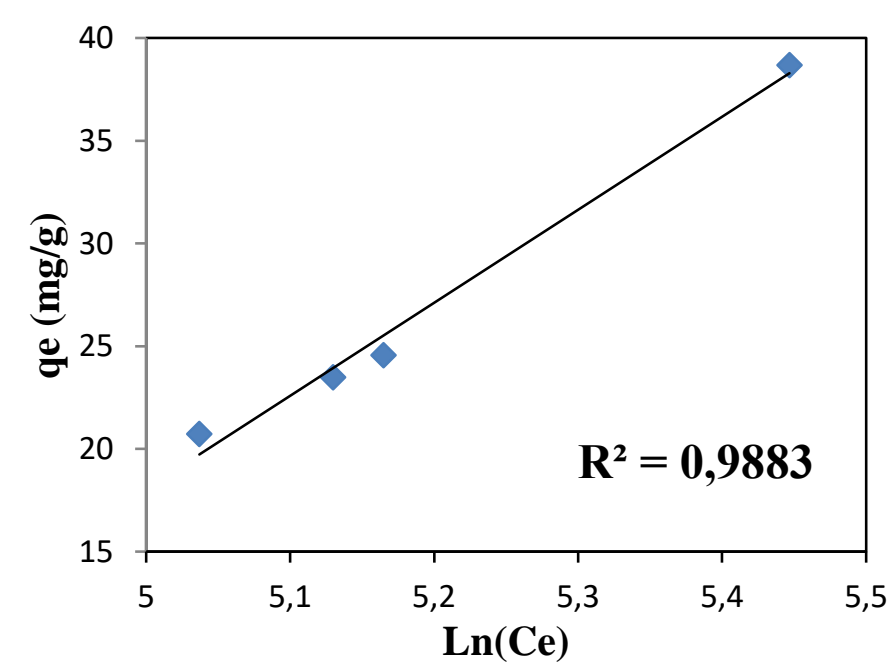

(c) Temkin

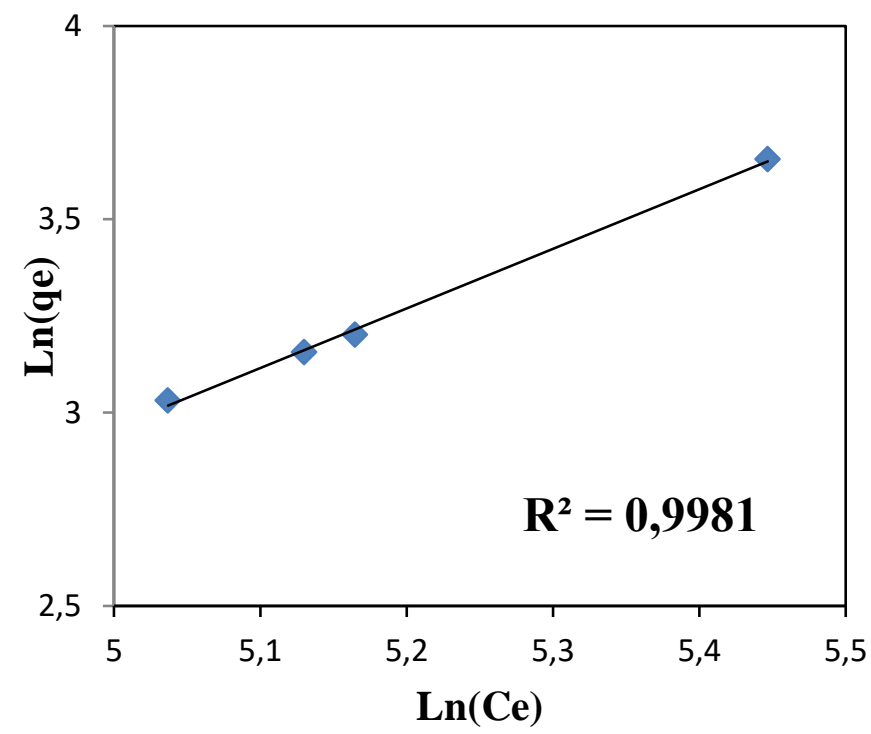

(b) Freundlich

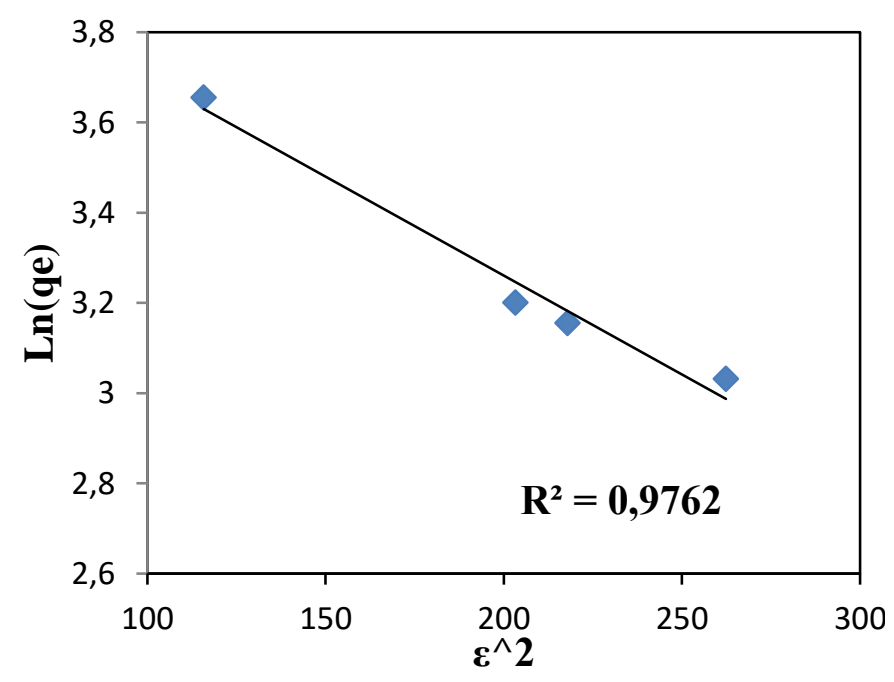

(d) Dubinin-Redushkevich

Şekil 1. İzoterm grafikleri (şartlar; temas süresi: 50 dakika, reçine ön kurutma süresi: 4 saat, adsorbent miktarı: ağırlıkça \%6, sicaklik: $\left.28^{\circ} \mathrm{C}\right)$. 
Şekil 1' de gösterilen izoterm eşitliklerinden elde edilen korelasyon katsayıları $\left(\mathrm{R}^{2}\right.$ değerleri) kullanılarak, onların uygulanabilirliği değerlendirilmiş ve her bir izoterm için elde edilen $\mathrm{R}^{2}$ değerleri Tablo 2' de verilmiştir. Ayrıca Şekil 1'deki grafiklerin eğimleri ve kaymalarından faydalanılarak her bir izoterme ait sabitler belirlenmiş ve bu sabitler de Tablo 2' de verilmiştir.

Tablo 2. Reçine ile biyodizelden suyun adsorpsiyonu için izoterm parametreleri (Şartlar; temas süresi: 50 dakika, reçine ön kurutma süresi: 4 saat, adsorbent miktarl: \%6 (ă̆ırlıkça), sicaklık: $28^{\circ} \mathrm{C}$ ).

\begin{tabular}{|c|c|c|}
\hline İzoterm modeli & Parametre & Değeri \\
\hline \multirow[t]{7}{*}{ Langmuir } & $\mathrm{q}_{\mathrm{m}}\left(\mathrm{mg} \mathrm{g}^{-1}\right)$ & 53.48 \\
\hline & $\mathrm{K}_{\mathrm{L}}\left(\mathrm{L} \mathrm{mg}^{-1}\right)$ & 0.0018 \\
\hline & $\mathrm{R}_{\mathrm{L}}$ & 0,284 (1398 mg/L için) \\
\hline & & 0,260 (1578 mg/L için) \\
\hline & & $0,251(1649 \mathrm{mg} / \mathrm{L}$ için $)$ \\
\hline & & $0,178(2553 \mathrm{mg} / \mathrm{L}$ için $)$ \\
\hline & $\mathrm{R}^{2}$ & 0.997 \\
\hline \multirow[t]{4}{*}{ Freundlich } & $\mathrm{n}\left(\mathrm{g} \mathrm{L}^{-1}\right)$ & 0.65 \\
\hline & $\mathrm{K}_{\mathrm{F}}\left(\left(\mathrm{mg} \mathrm{g}^{-1}\right)\left(\mathrm{L} \mathrm{mg}^{-1}\right)^{1 / n}\right.$ & 0.0087 \\
\hline & $\mathrm{R}^{2}$ & 0.998 \\
\hline & $\mathrm{B}_{\mathrm{T}}$ & 45.281 \\
\hline \multirow[t]{3}{*}{ Temkin } & $\mathrm{K}_{\mathrm{T}}\left(\mathrm{L} \mathrm{mg}^{-1}\right)$ & 0.010 \\
\hline & $\mathrm{R}^{2}$ & 0.988 \\
\hline & $\mathrm{qm}\left(\mathrm{mg} \mathrm{g}^{-1}\right)$ & 62.66 \\
\hline \multirow[t]{3}{*}{ Dubinin-Radushkevich } & $\mathrm{K}_{\mathrm{DR}}\left(\mathrm{mol}^{2} \mathrm{j}^{-2}\right)$ & 0.0044 \\
\hline & $\mathrm{E}\left(\mathrm{kj} \mathrm{mol}^{-1}\right)$ & 0.011 \\
\hline & $\mathrm{R}^{2}$ & 0.976 \\
\hline
\end{tabular}

Reçine üzerine suyun adsorpsiyon izotermleri, Tablo 2' de verilen deneysel şartlar altında ve $1398,1578,1649$ ve $2553 \mathrm{mgL}^{-1} \mathrm{su}^{\mathrm{s}}$ konsantrasyonlarına sahip biyodizel numuneleri kullanılarak incelenmiştir.

Dowex HCR-S katyonik reçinesi ile suyun adsorplanma prosesinin hangi izoterme uyduğunu belirlemek için, ilk olarak Şekil 1' de çizilen grafiklerin $\mathrm{R}^{2}$ değerlerine bakılmıştır. Tablo 2 incelendiğinde, Temkin ve Dubinin-Radushkevich izotermlerinin $\mathrm{R}^{2}$ değerlerinin, Langmuir ve Freundlich izotermlerinden küçük olduğu görülmüştür. Bu nedenle, mevcut prosesin bu izotermlere uymadığına karar verilmiştir. Ancak Langmuir ve Freundlich izotermlerinin $\mathrm{R}^{2}$ değerlerinin birbirine çok yakın olduğu görülmüştür. Bu nedenle reçine ile su adsorpsiyon prosesinin bu iki adsorpsiyon izoterm grubundan hangisine girdiğini incelemek için, qe teorik değerleri hesaplanmış ve qe deneysel değeri ile karşılaştırılmış (Tablo 3) ve deneysel ve teorik qe'leri birbirine en yakın olan izoterm tercih edilmiştir. Tablo 3' deki deneysel qe, $\mathrm{Co}=1398 \mathrm{mg} / \mathrm{L}$ başlangıç konsantrasyonu baz alınarak hesaplanmıştır (Eşitlik 11). Ayrıca, Langmuir izotermi için teorik qe, Eşitlik 1 ve Freundlich izotermi için teorik qe ise Eşitlik 3 kullanılarak hesaplanmış ve bu değerler Tablo 3' de verilmiştir.

$$
q_{e}=\frac{\left(C_{o}-C_{e}\right)}{m} x V
$$

Burada, V, biyodizel hacmi (L) ve m, reçine miktarıdır (g)' dır. 
Tablo 3. Langmuir ve Freundlich izotermleri için deneysel ve teorik qe değerleri

\begin{tabular}{llll}
\hline Langmuir İzotermi & & Freundlich İzotermi & \\
\hline Deneysel qe & Teorik qe & Deneysel qe & Teorik qe \\
20.733 & 20.629 & 20.733 & 1.932 \\
\hline
\end{tabular}

Tablo 3' de görüldüğü gibi, Langmuir izotermi için deneysel ve teorik qe değerleri birbirine çok yakındır. Bu nedenle, mevcut adsorpsiyonun Langmuir izotermine uyduğuna karar verilmiştir. Ayrıca Langmuir izotermine ait önemli bir boyutsuz sayı olan $\mathrm{R}_{\mathrm{L}}$ değerlerinin, $0.284,0.260,0.251$ ve 0.178 oldukları görülmüştür. Bu değerler, $0<\mathrm{RL}<1$ olduğu için, kullanılan reçinenin adsorpsiyon için uygun olduğunu göstermiştir. Freundlich izotermindeki, n değerinin 0.65 olması $(\mathrm{n}<1)$ ve D-R izoterminde E değerinin 0.011 $\mathrm{kj} / \mathrm{mol}$ olması $(\mathrm{E}<8 \mathrm{kj} / \mathrm{mol})$ olması ise adsorpsiyonun fiziksel olduğunu göstermiştir.

\subsection{Adsorpsiyon Kinetiği}

Deneysel verileri farklı kinetik modellere uydurmak, adsorpsiyon hızını, prosesin modelini ve adsorbent/adsorbat arasındaki etkileşimin fiziksel mi yoksa kimyasal mı olduğu hakkında tahmini bilgileri incelememizi sağlar (Elmorsi ve ark, 2014). Bu çalışmada yalancı birinci mertebe ve yalancı ikinci mertebe olmak üzere iki farklı kinetik model kullanılmıştır (Gündüz ve Bayrak, 2017).

\subsubsection{Yalancı Birinci Mertebe Eşitliği}

Yalancı birinci mertebe eşitliği, adsorpsiyon prosesinin hız sabitini bulmak için Langergren ve Svenska tarafından verilmiştir (Eşitlik 12).

$$
\log \left(q_{e}-q_{t}\right)=\log q_{e}-\frac{K_{1}}{2.303} t
$$

Burada, qe ( $\left.\mathrm{mg} \mathrm{g}^{-1}\right)$ ve qt $\left(\mathrm{mg} \mathrm{g}^{-1}\right)$, sırasıyla denge ve herhangi bir t süresindeki adsorpsiyon kapasiteleri ve $\mathrm{K}_{1}\left(\right.$ dakika $\left.{ }^{-1}\right)$, yalancı birinci mertebe hız sabiti (Rudzinski ve Plazinski, 2006).

Burada, t' ye karşı, log (qe-qt) değerleri, iki farklı konsantrasyon için (1398, $\left.1578 \mathrm{mg} \mathrm{L}^{-1}\right)$ doğrusal olarak grafik edilmiş (Şekil 2a) ve bu doğrunun eğimi ve kaymasından $\mathrm{K}_{1}$ ve qe değerleri hesaplanmış ve bu değerler Tablo 4' de verilmiştir. Tablo 4' deki sonuçlar, $\mathrm{R}^{2}$ değerlerinin düşük, deneysel qe değerlerinin ise hesaplanan qe değerleri ile uyuşmadığını göstermektedir. Bu da bize, Dowex HCR$\mathrm{S}$ reçine ile biyodizelden su adsorpsiyonunun yalancı 1 mertebe kinetiğe uymadığını göstermektedir.

\subsubsection{Yalancı İkinci Mertebe Hız Eşitliğ̈i}

Yalancı ikinci mertebe kinetik mıdeli şu şekilde verilebilir:

$$
\frac{t}{q_{t}}=\frac{1}{\left(K_{2} q_{e}^{2}\right)}+\left(\frac{1}{q_{e}}\right) x t
$$

Burada, $\mathrm{K}_{2}\left(\mathrm{~g} \mathrm{mg}^{-1} \mathrm{dak}^{-1}\right)$, yalancı ikinci mertebe hız sabitidir (Rudzinski ve Plazinski, 2006).

Burada, t' ye karşı, t/qt değerleri, iki farklı konsantrasyon için (1398, $\left.1578 \mathrm{mg} \mathrm{L}^{-1}\right)$ doğrusal olarak grafik edilmiş (Şekil 2-b) ve bu doğrunun eğimi ve kaymasından $\mathrm{K}_{2}$ ve qe değerleri hesaplanmış ve bu değerler Tablo 4' de verilmiştir. 


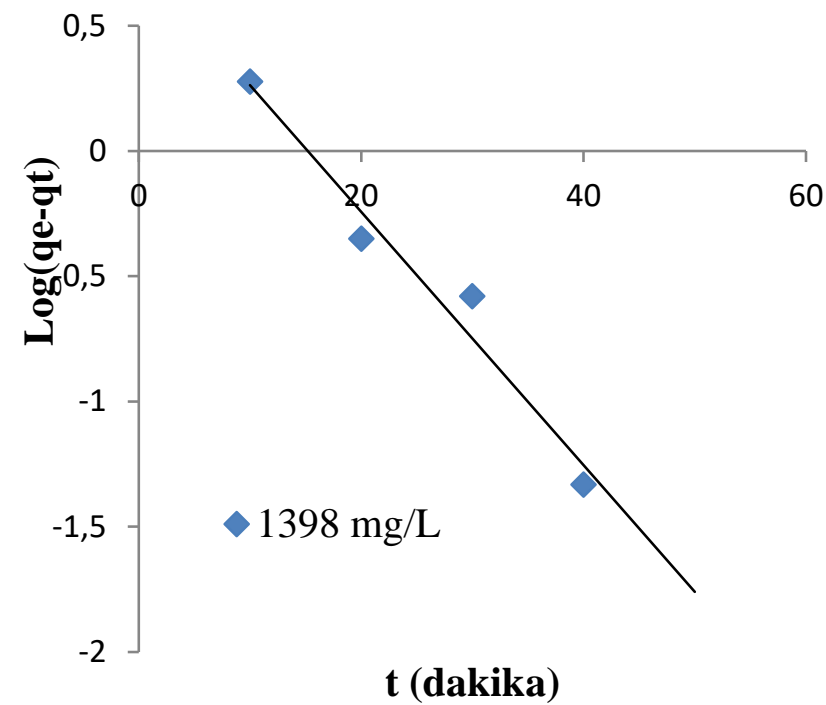

(a) Yalancı birinci mertebe kinetik model

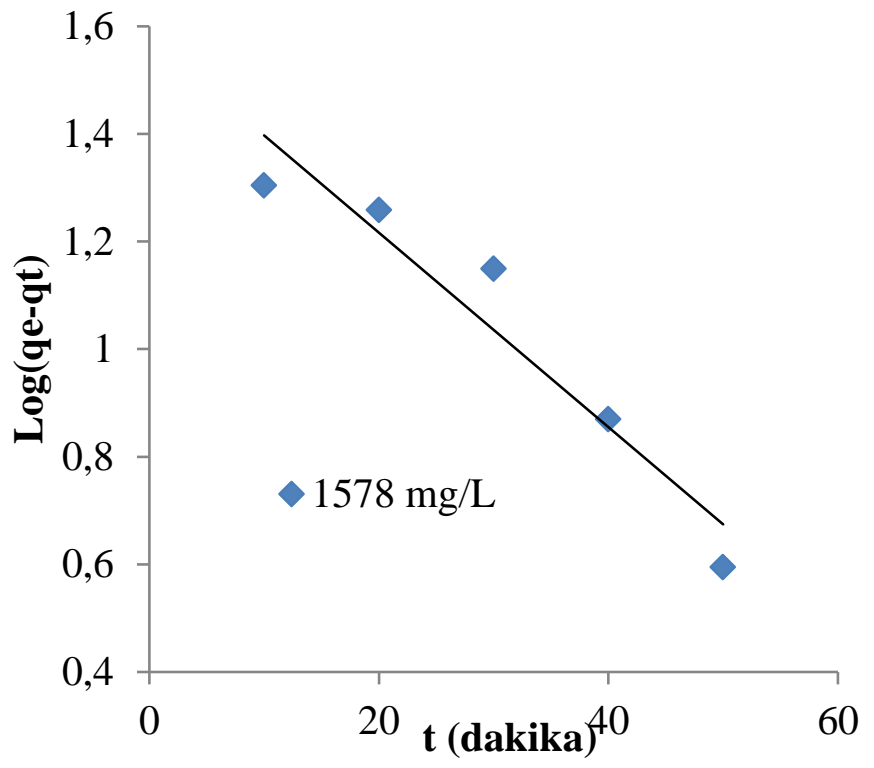

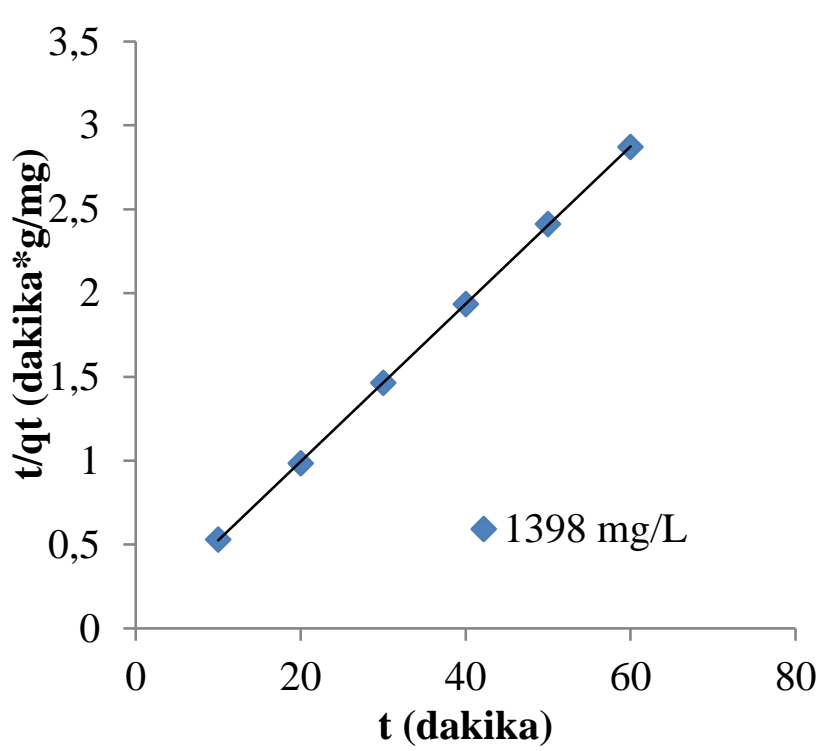

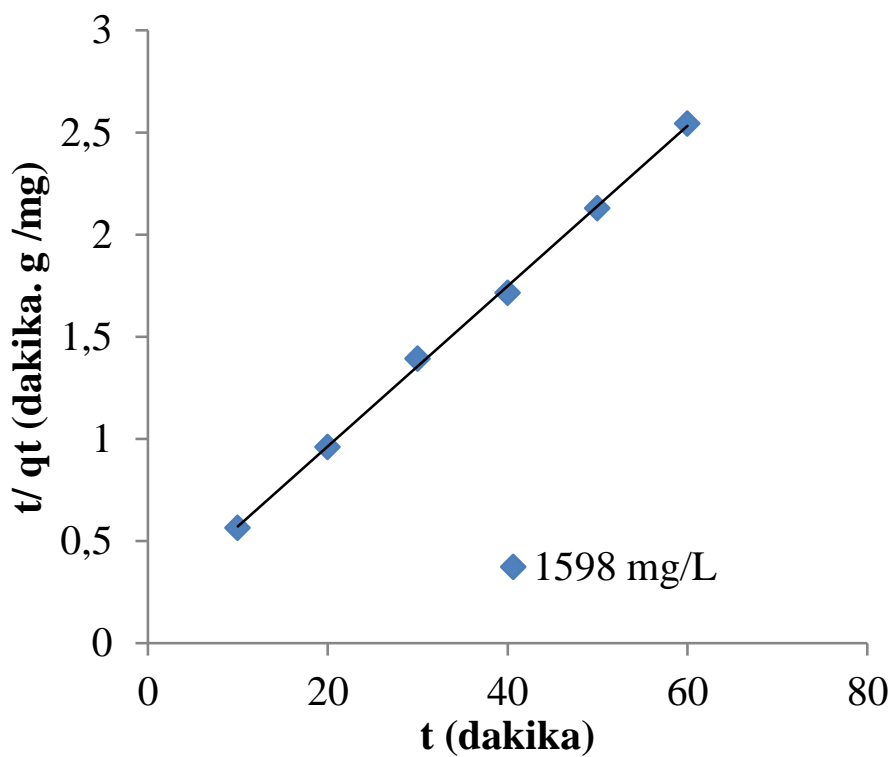

(b) Yalanc1 ikinci mertebe kinetik model

Şekil 2. Kinetik modeller (şartlar; sıcaklık: $28^{\circ} \mathrm{C}$, adsorbent miktarı: ăğılıkça \%6, reçine ön kurutma süresi: 4 saat)

Şekil 2b’ deki sonuçlar, çok yüksek $\mathrm{R}^{2}$ değerlerine sahip doğrular göstermektedir. Buna ilaveten, deneysel qe değerleri ile hesaplanan qe değerleri arasında iyi bir uyum vardır (Tablo 4). Bu nedenle, yalancı ikinci mertebe kinetik modelin bu proses için uygun olduğuna karar verilmiştir.

Tablo 4. Reçine ile biyodizeldeki suyun adsorpsiyonu için adsorpsiyon kinetik parametreleri (sıcaklık: $28^{\circ} \mathrm{C}$, reçine ön kurutma süresi: 4 saat, reçine miktarı: ă̆ırlıkça\%6).

\begin{tabular}{|c|c|c|c|c|}
\hline Kinetik model & Kinetik parametreler & & & \\
\hline $\begin{array}{l}\text { Yalancı birinci } \\
\text { mertebe }\end{array}$ & $\mathrm{K}_{1}\left(\right.$ dakika $\left.^{-1}\right)$ & $\begin{array}{l}\text { qe }\left(\mathrm{mg} \mathrm{g}^{-1}\right) \\
\text { (hesaplanan) }\end{array}$ & $\begin{array}{l}\text { qe }\left(\mathrm{mg} \mathrm{g}^{-1}\right) \\
\text { (deneysel) }\end{array}$ & $\mathrm{R}^{2}$ \\
\hline $1398 \mathrm{mg} / \mathrm{L}$ & 0.117 & 5.87 & 20.73 & 0.965 \\
\hline $1578 \mathrm{mg} / \mathrm{L}$ & 0.042 & 37.84 & 23.43 & 0.917 \\
\hline
\end{tabular}


Yalancı ikinci

mertebe

$1398 \mathrm{mg} / \mathrm{L}$

$1578 \mathrm{mg} / \mathrm{L}$
$\mathrm{K}_{2}\left(\mathrm{mg} \mathrm{g}^{-1}\right.$ dak. $\left.^{-1}\right)$

0.040

0.009 qe $\left(\mathrm{mg} \mathrm{g}^{-1}\right)$

(hesaplanan)

21.28

25.51 qe $\left(\mathrm{mg} \mathrm{g}^{-1}\right)$

(deneysel)

20.73

23.43
$\mathrm{R}^{2}$

1 0.99

\subsection{Termodinamik Analizler}

Termodinamik analizler, $15^{\circ} \mathrm{C}, 28^{\circ} \mathrm{C}, 40^{\circ} \mathrm{C}$ ve $50^{\circ} \mathrm{C}$ olmak üzere dört farklı sıcaklıkta yapılmıştır. Standart serbest enerji değişimi $\left(\Delta \mathrm{G}^{\mathrm{o}}\right)$, entalpi değişimi $\left(\Delta \mathrm{H}^{\circ}\right)$ ve entropi değişimi $\left(\Delta \mathrm{S}^{\circ}\right)$ gibi termodinamik parametreler, aşağıdaki eşitlikler kullanılarak hesaplanmıştır.

$$
K_{D}=\frac{q_{e}}{C_{e}}
$$

Burada $K_{D}$ (dağılım katsayısı), adsorbent yüzeyinin ilgisini ortaya koyar. Gibbs serbest enerjisi, Eşitlik 15 kullanılarak bulunmuş ve Tablo 5' de sunulmuştur.

$$
\Delta G^{o}=-R T \ln K_{D}
$$

$\Delta \mathrm{H}^{\mathrm{o}}$ ve $\Delta \mathrm{S}^{\mathrm{o}}$ değerleri, Eşitlik 16 (Van’t Hoff eşitliği) kullanılarak bulunmuştur.

$$
\ln K_{D}=\frac{\Delta S^{o}}{R}-\frac{\Delta H^{o}}{R T}
$$

Burada, R (8.314 $\left.\mathrm{J} \mathrm{mol}^{-1} \mathrm{~K}^{-1}\right)$, gaz sabiti ve T (K), mutlak sıcaklıktır.

Burada, 1/T' ye karşı $\ln K_{D}$ doğrusal olarak grafik edilmiş (Şekil 3), elde edilen doğrunun eğimi ve kaymasından ise $\Delta H^{\circ}$ ve $\Delta \mathrm{S}^{\circ}$ değerleri bulunmuştur (Tablo 5).

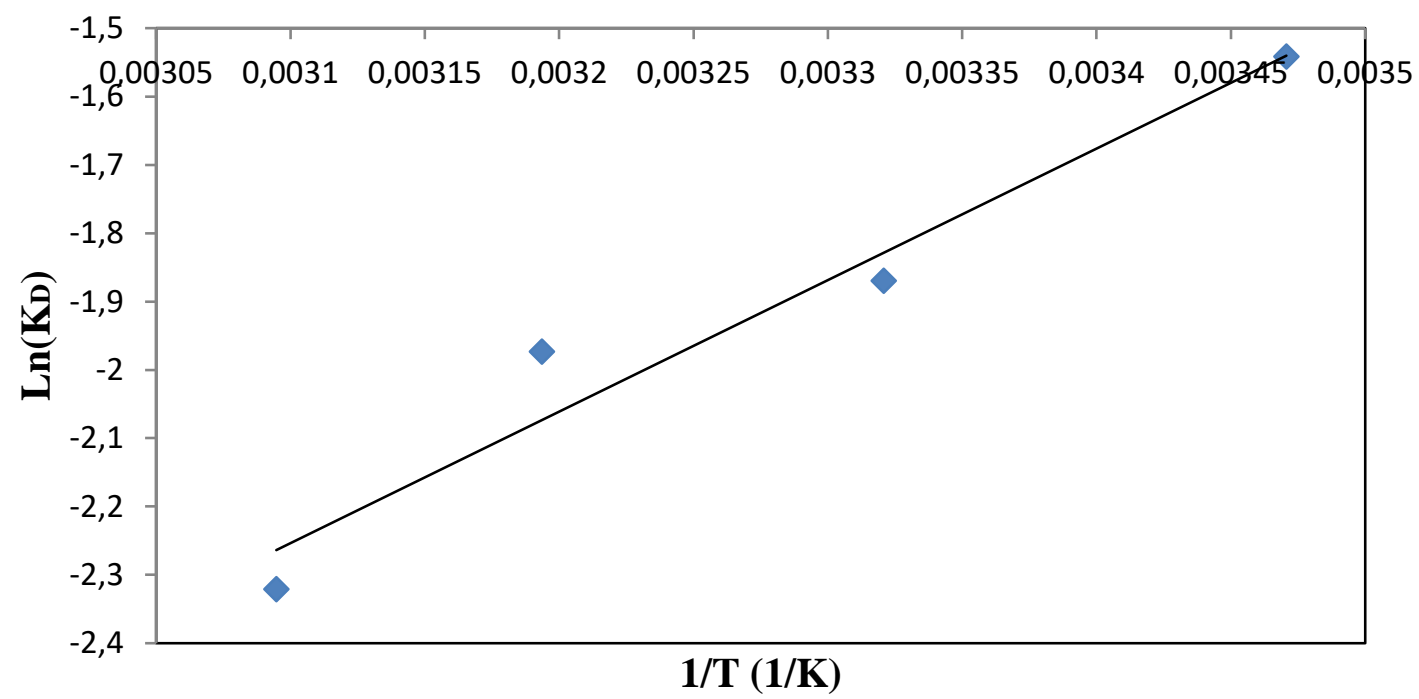

Şekil 3. Van't Hoff eşitliğ grafiği

Tablo 5 incelendiğinde, $\Delta \mathrm{H}^{0}<0$ olması, bu prosesin ekzotermik olduğunu ve düşük sıcaklıkların adsorpsiyonun lehine olduğunu, $\Delta \mathrm{G}^{\mathrm{o}}$ değerlerinin negatif olması ise adsorpsiyonun kendiliğinden gerçekleştiğini göstermektedir. Ayrıca $\Delta \mathrm{G}^{\circ}$ ' 1 in mutlak değerlerinin 20 $\mathrm{kj} \mathrm{mol}^{-1}$ den daha büyük olması ise, Dowex HCR-S reçine ile biyodizeldeki suyun adsorpsiyon prosesinin fiziksel adsorpsiyon olduğunu göstermektedir (Li ve ark, 2019).

Tablo 5. Reçine üzerine suyun adsorpsiyonu için termodinamik parametreler

\begin{tabular}{llll}
\hline $\mathrm{T}\left({ }^{\circ} \mathrm{C}\right)$ & $\Delta \mathrm{H}^{\mathrm{o}}\left(\mathrm{kJ} \mathrm{mol}^{-1}\right)$ & $\Delta \mathrm{S}^{\mathrm{o}}\left(\mathrm{kJ} \mathrm{mol}^{-1} \mathrm{~K}^{-1}\right)$ & $\Delta \mathrm{G}^{\mathrm{o}}\left(\mathrm{kJ} \mathrm{mol}^{-1}\right)$ \\
\hline 15 & -16.00 & 0.07 & -35.69 \\
28 & -16.00 & 0.07 & -36.58 \\
40 & -16.00 & 0.07 & -37.40 \\
50 & -16.00 & 0.07 & -38.08 \\
\hline
\end{tabular}




\section{Sonuç}

$\mathrm{Bu}$ çalışmada adsorbent olarak kullanılan Dowex HCR-S reçine üzerine biyodizeldeki suyun adsorpsiyonunun izoterm, kinetik ve termodinamik açıdan incelemesi yapılmış ve sonuçlar aşağıda sunulmuştur.

- Deneysel verilerin Langmuir, Freundlich, Temkin ve Dubinin-Radushkevich izotermlerine uygunluğu analiz edilmiş ve en uygun izotermin Langmuir olduğu ve ayrıca kullanılan reçinenin adsorpsiyon için uygun olduğu bulunmuştur.

- Prosesin yalanci ikinci mertebe kinetik modele uyduğu belirlenmiştir.

- Termodinamik analizler, prosesin ekzotermik olduğunu, kendiliğinden gerçekleştiğini ve fiziksel adsorpsiyon olduğunu göstermiştir.

\section{Kaynakça}

Alves, M.J., Cavalcanti, I.V., Resende, M.M., Cardoso, V.L., Reis, M.H. (2016). Biodiesel dry purification with sugarcane bagasse, Industrial Crops and Products, 89, 119-127.

Andrei, M. (2016). Aspects Related to the Purification of Biodiesel Synthesized in Alkaline Catalysis, Revista De Chime, 67(4), 791795.

Atadashi, I.M. (2015). Purification of crude biodiesel using dry washing and membrane technologies. Alexandria Engineering Journal, 54 (4), 1265-1272.

Atadashi, I.M., Aroua, M.K., Abdul Aziz, A.R., Sulaiman, N.M.N. (2012). The effects of water on biodiesel production and refining technologies: A review. Renewable and Sustainable Energy Reviews, 16, 3456-3470.

Berrios, M., Martin, M.A., Chica A.F., Martin, A. (2011). Purification of biodiesel from used cooking oils. Applied Energy, 88, 36253631.

Çelik-Okumuş, Z., Doğan, T.H., Temur, H. (2019). Removal of water by using cationic resin during biodiesel purification. Renewable Energy, Accepted for publication.

Dubinin, M., Radushkevich, L. (1947). Equation of the characteristic curve of activated charcoal. Chemisches Zentralblatt, 1, 875.

Elmorsi, T.M., Mohamed, Z.H., Shopak, W., Ismaiel, A.M. (2014). Kinetic and Equilibrium Isotherms Studies of Adsorption of Pb(II) from Water onto Natural Adsorbent. Journal of Environmental Protection, 5, 1667-1681.

Faccini, C.S., da Cunha, M.E., Aranda Moraes, M.S., Krause, L.C., Manique, M.C., Rodrigues, M.R.A., Benvenutti, E.V., Caramao, E.B. (2011). Dry washing in biodiesel purification: a comparative study of adsorbents. Journal of the Brazilian Chemical Society, $22,558-563$.

Gündüz, F., Bayrak, B. (2017). Biosorption of malachite green from an aqueous solution using pomegranate peel: Equilibrium modelling, kinetic and thermodynamic studies. Journal of Molecular Liquids, 243, 790-798.

Hayyan, M., Mjalli, F.S, Hashim, M.A., Alnashef, I.M. (2010). A novel technique for separating glycerine from palm oil-based biodiesel using ionic liquids. Fuel Processing Technology, 91, 116-120.

Kanca, A., Temur, H. (2016). The effects of long-term storage on the cold flow properties and viscosity of canola-based biodiesel. Energy Sources, Part A: Recovery, Utilization, and Environmental Effects, 38(15), 2205-2210.

Kusdiana, D., Saka, S. (2004). Effects of water on biodiesel fuel production by supercritical methanol treatment. Bioresource Technology, 91 (3), 289-295.

Langmuir, I. (1918). The adsorption of gases on plane surfaces of glass, mica and platinum, Journal of the American Chemical Society, 40, 1361-1403.

Li, R., Liang, N., Ma, X., Chen, B., Huang, F. (2019). Study on the adsorption behavior of glycerin from fatty acid methyl esters by a tertiary amine-type anion exchange resin. Journal of Chromatography A, 1586, 62-71.

Ma, F., Hanna, M. A. (1999). Biodiesel production: A review. Bioresour Technology, 70, 1-15.

Özgül-Yücel, S., Türkay, S. (2003). Purification of FAME by rice hull ash adsorption. Journal of the American Oil Chemists's Society, 80, 373-376.

Rudzinski, W., Plazinski, W. (2006). Kinetics of Solute Adsorption at Solid/Solution Interfaces: A Theoretical Development of the Empirical Pseudo-First and Pseudo-Second Order Kinetic Rate Equations, Based on Applying the Statistical Rate Theory of Interfacial Transport. The Journal of Physical Chemistry B, 110, 16514-16525.

Shadid, E.M., Jamal, Y. (2011). Production of biodiesel: A technical review. Renewable and Sustainable Energy Reviews, 15, 47324745.

Shibasaki-Kitakawa, N., Kanagawa, K., Nakashima, K., Yonemoto, T. (2013). Simultaneous production of high quality biodiesel and glycerin from Jatrophaoil using ion-exchange resins as catalysts and adsorbent. Bioresource Technology, 142, 732-736.

Temkin, M., Pyzhev, V. (1940). Recent Modifications to Langmuir isotherms. Acta Physico-Chimica Sinica, 12, 217-222.

Veljkovic, V.B., Bankovic-llic, I.B., Stamenkovic, O.S. (2015). Purification of crude biodiesel obtained by heterogeneously-catalyzed transesterification. Renewable and Sustainable Energy Reviews, 49, 500-516.

Wall, J., Van Gerpen, J., Thompson, J. (2011). Soap and glycerin removal from biodiesel using waterless processes. Transactions of the Asabe, 54, 535-541. 